\title{
Arithmetic-Geometric Mean: Evaluation of Parameter from Observed Data Containing Itself and Random Error
}

\author{
Dhritikesh Chakrabarty \\ Department of Statistics, Handique Girls' College, Guwahati, Assam, India \\ dhritikesh.c@rediffmail.com,dhritikeshchakrabarty@gmail.com
}

\begin{abstract}
Recently some methods have been developed for determining the value of parameter from observed data containing a single parameter and random error since the existing statistical methods of estimation in such situation fail in finding out the appropriate value of the parameter. The methods, so developed, involve huge computational tasks. Moreover, a finite set of observed data may not yield the appropriate value of the parameter in many situations while the number of observations required in the methods may be too large for obtaining the appropriate value of the parameter. For these two limitations, one method for the same has been developed here which involves lesser computational tasks than those involved in the methods developed so far. Moreover, the method described here can be applicable in the case of finite set of data. This paper describes the derivation of the method and one numerical application of the method in determining the central tendency of each of annual maximum and annual minimum of surface air temperature at Guwahati.
\end{abstract}

Key words: 1; AGM 2; parameter 3; random error 4; evaluation of parameter 5; surface air temperature 6; central tendency

\section{Introduction:}

There are many situations where the observions are composed of some parameter and random errors i.e. the observations

$$
x_{1}, x_{2}, \ldots \ldots \ldots . ., x_{n}
$$

are composed of some parameter $\mu$ and random errors $\varepsilon_{i}$ which implies

Copyright @ESES

https://doi.org/10.33665/IJEAR.2019.v06i02.003
IJEAR

98 


$$
x_{i}=\mu+\varepsilon_{i}, \quad(i=1,2, \ldots \ldots \ldots, n)
$$

[Chakrabarty $(2014 a, 2014 b$, 2014c , 2015a , 2015b , 2015c , 2015d , 2015e]. The existing methods of estimation of $\mu$ namely least squares method, maximum likelihood method, minimum variance unbiased method, method of moment and method of minimum chi-square, [Aldrich (2000.), Anders (1999), Barnard (1949), Birnbaum (1962), Ivory (1825), Kendall \& Stuart (1977), Lehmann \& Casella George (1998), Lucien (1990), Walker \& Lev (1965)] provides $T$ as estimator of the parameter $\mu$ where $T$ is given by

$$
T=\frac{1}{n} \sum_{\mathrm{i}=1}^{n} x_{i}
$$

It has been shown that this estimator $T$ of the parameter $\mu$ suffers from an error $e$ given by

$$
e=\frac{1}{n} \sum_{i=1}^{n} \varepsilon_{i}
$$

which is not zero usually. In other words, none of these methods can provide appropriate value of the parameter $\mu$ [Chakrabarty $(2014 a, 2014 b, 2014 c)]$.

In some recent studies, some methods have been developed for determining the appropriate value of the parameter $\mu$ involved in the model described by equation(1.1) [Chakrabarty (2014a , 2014b , 2014c , 2015a , 2015b , 2015c , 2015d , 2015e , 2015f , 2016a , 2016b , 2019a , 2019c]. In these studies some methods have been developed for determining the appropriate value of the parameter $\mu$ when $\varepsilon_{i}$ occurs due to random cause.

The first method, developed for the same is based on computing sequence of interval value of $\mu$ with decreasing length of interval and then to find out the shortest interval value of $\mu$ [Chakrabarty $(2014 a, 2014 b, 2014 c, 2015 d)$ ] while the second one is based on stable mid range and median (Chakrabarty , 2015b) and the third one on the convergence of statistic i.e. some function of the available numerical data (Chakrabarty , 2017). The fourth one (Chakrabarty , 2018a) has been developed on the basis of Pythagorean means [Kolmogorov (1930), O'Meara (1989) , Riedweg (2005), Cornelli, McKirahan \& Macris (2013), de Carvalho (2016) , Chakrabarty $(2018 b, 2018 c, 2018 d, 2018 e, 2019 d, 2019 e$ ] while the fifth one (Chakrabarty , $2019 b$ ) for the same is based on the probabilistic convergence of Pythagorean means. 
The methods, developed so far for determining thr appropriate value of the parameter from observed data containing the parameter itself and random error, involve huge computational tasks. Moreover, a finite set of observed data may not yield the appropriate value of the parameter in many situations while the number of observations required in the methods may be too large for obtaining the appropriate value of the parameter. For these two probable drawbacks, one method for the same purpose has been developed here which involves lesser computational tasks than those involved in the methods developed so far. Moreover, the method described here can be applicable in the case of finite set of data. This paper describes the derivation of the method and one numerical application of the method in determining the central tendency of each of annual maximum and annual minimum of surface air temperature at Guwahati.

\section{Arithmetic-Geometric Mean (AGM):}

In mathematics, the arithmetic-geometric mean (AGM) [David (2004), Hazewinkel (2001)], of two positive real numbers $x$ and $y$ is defined as follows:

Let us denote $x \& y$ by $a_{0} \& g_{0}$ respectively.

Then define the two interdependent sequences $\left\{a_{n}\right\}$ and $\left\{g_{n}\right\}$ by

$$
a_{n+1}=1 / 2\left(a_{n}+g_{n}\right) \quad \& \quad g_{n+1}=\left(a_{n} g_{n}\right)^{1 / 2}
$$

where the square root takes the principal value.

These two sequences converge to the same number, called the Arithmetic-Geometric Mean (abbreviated by AGM) of $x \& y$; which is denoted by $M(x, y)$ or sometimes by $\operatorname{agm}(x, y)$.

Proof of Existence of $M(x, y)$

The three Pythagorean means namely Arithmetic Mean (AM), Geometric Mean (GM) \& Harmonic Mean (HM) satisfy the inequality

$$
\mathrm{AM} \geq \mathrm{GM} \geq \mathrm{HM}
$$

From the inequality one can conclude that

$$
g_{n} \leq a_{n}
$$

and thus

$$
g_{n+1}=\left(a_{n} g_{n}\right)^{1 / 2} \geq\left(g_{n} g_{n}\right)^{1 / 2}=g_{n}
$$

$$
\text { i.e. } \quad g_{n+1} \geq g_{n} \text { since }\left(g_{n} g_{n}\right)^{1 / 2}=g_{n}
$$

This means that the sequence $\left\{g_{n}\right\}$ is nondecreasing. 
Moreover, the sequence $\left\{g_{n}\right\}$ is bounded above by the larger of $x$ and $y$ (which follows from the fact that both the arithmetic and geometric means of two numbers lie between them).

In the mathematical field of real analysis, the monotone convergence theorem [Weir (1973), Yeh (2006)] states that if a sequence is increasing and bounded above by a supremum, then the sequence will converge to the supremum; in the same way, if a sequence is decreasing and is bounded below by an infimum, it will converge to the infimum.

Thus, by the monotone convergence theorem, the sequence is convergent.

Therefore, there exists a finite number $g$ such that

$$
g_{n} \text { converges to } g \text { as } n \text { approaches infinity. }
$$

Again, $a_{n}$ can be expressed as

$$
a_{n}=\frac{g_{n+1} 2}{g_{n}}
$$

This implies that the limiting value of $a_{n}$ as $n$ approaches infinity is $g$.

Therefore, $a_{n}$ converges to $g$ as $n$ approaches infinity.

Thus, both of $a_{n} \& g_{n}$ converges to $g$ as $n$ approaches infinity.

\section{Evaluation of $\boldsymbol{\mu}$}

If the observations

$$
x_{1}, x_{2}, \ldots \ldots \ldots ., x_{N}
$$

are composed of some parameter $\mu$ and random errors then the observations can be expressed as

$$
x_{i}=\mu+\varepsilon_{i} \quad, \quad(i=1,2, \ldots \ldots \ldots ., N)
$$

where

(i) $x_{1}, x_{2}, \ldots \ldots \ldots . ., x_{N}$ are observed data,

(ii) $\mu$ is the parameter

$\&$ (iii) $\varepsilon_{1}, \varepsilon_{2}, \ldots \ldots \ldots \ldots, \varepsilon_{N}$ are the random errors associated to

$$
x_{1}, x_{2}, \ldots \ldots \ldots \ldots, x_{N}
$$

respectively which assume positive and negative values in random order. 
In this situation,

$$
A\left(x_{1}, x_{2}, \ldots \ldots \ldots \ldots, x_{N}\right) \rightarrow \mu \text { as } N \rightarrow \infty
$$

where

$$
A\left(x_{1}, x_{2}, \ldots \ldots \ldots . . ., x_{N}\right)=\frac{1}{N} \sum_{i=1}^{N} x_{\mathrm{i}}
$$

and

$$
G\left(x_{1}, x_{2}, \ldots \ldots \ldots \ldots, x_{N}\right) \rightarrow \mu \text { as } N \rightarrow \infty
$$

where

$$
G\left(x_{1}, x_{2}, \ldots . . \ldots . ., x_{N}\right)=\left(\prod_{i=1}^{N} e_{i}\right)^{1 / \mathrm{N}}
$$

This implies that the common converging value of $A\left(x_{1}, x_{2}, \ldots \ldots \ldots ., x_{N}\right)$ and $G\left(x_{1}, x_{2}, \ldots . . \ldots . ., x_{N}\right)$ is the value of $\mu$.

It is to be noted that the converging value may not be possible to be obtained for a finite set of observed values namely

$$
x_{1}, x_{2}, \ldots \ldots \ldots \ldots, x_{N}
$$

In order to obtain the value of $\mu$, in this case, let us write

$$
\begin{aligned}
A\left(x_{1}, x_{2}, \ldots . . . \ldots . ., x_{N}\right) & =A_{0} \\
\& & G\left(x_{1}, x_{2}, \ldots . . . \ldots ., x_{N}\right)=G_{0}
\end{aligned}
$$

and then define the two interdependent sequences $\left\{A_{n}\right\}$ and $\left\{G_{n}\right\}$ as

$$
\begin{gathered}
A_{n+1}=1 / 2\left(A_{n}+G_{n}\right) \\
\& G_{n+1}=\left(A_{n} G_{n}\right)^{1 / 2}
\end{gathered}
$$

Then, both of $A_{n} \& G_{n}$ converges to $C$ as $n$ approaches infinity.

Now, it is required to verify whether this $C$ is equal to $\mu$.

From the model it is obtained that

$$
A_{0}=\mu+\varepsilon_{0} \quad \& \quad G_{0}=\mu+e_{0}
$$

The inequality of Pythagorean means namely

\section{$\mathrm{AM} \geq \mathrm{GM}$}

implies that $\quad A_{0} \geq G_{0}$ i.e. $\varepsilon_{0} \geq e_{0}$

Thus $A_{1}=\mu+\varepsilon_{1} \quad$ where $\quad \varepsilon_{1}=1 / 2\left(\varepsilon_{0}+e_{0}\right) \leq \varepsilon_{0}$

In general, corresponding to $A_{n+1}$, it holds that 


$$
\varepsilon_{n+1}=1 / 2\left(\varepsilon_{n}+e_{n}\right) \leq \varepsilon_{n}
$$

This implies $\varepsilon_{n}$ converges to 0 i.e. $A_{n}$ converges to $\mu$.

By the existence of AGM, $G_{n}$ also converges to $\mu$.

\section{Application to Numerical Data:}

Observed data considered here are the data on each of annual maximum \& annual minimum of surface air temperature, occurred in temperature periodic year (TPR), at Guwahati during the period from 1969 to 2013. The objective here is to evaluatethe central tendency of each of annual maximum \& annual minimum of surface air temperature at Guwahati

\subsection{Annual Maximum of Surface Air Temperature at Guwahati:}

The following table (Table - 3.1.1) shows the observed data on annual maximum of surface air temperature, occurred in temperature periodic year (TPR), at Guwahati during the period from 1969 to 2013:

Table - 3.1.1

Observed Value on Annual Maximum of Surface Air Temperature (in Degree Celsius)

\begin{tabular}{|c|c|c|c|c|c|c|c|}
\hline $\begin{array}{c}\text { TPR No } \\
(i)\end{array}$ & Observed & TPR No & Observed & TPR No & Observed & TPR No & Observed \\
$(i)$ & Value $\left(x_{i}\right)$ & $(i)$ & Value $\left(x_{i}\right)$ & $\begin{array}{c}(i) \\
\text { Value }\left(x_{i}\right)\end{array}$ \\
\hline 1 & 37.1 & 12 & 35.1 & 23 & 37.4 & 34 & 38.0 \\
\hline 2 & 36.6 & 13 & 35.8 & 24 & 39.4 & 35 & 36.6 \\
\hline 3 & 36.0 & 14 & 36.5 & 25 & 36.4 & 36 & 38.0 \\
\hline 4 & 35.7 & 15 & 36.7 & 26 & 38.1 & 37 & 37.3 \\
\hline 5 & 39.0 & 16 & 37.2 & 27 & 36.3 & 38 & 37.3 \\
\hline 6 & 36.1 & 17 & 36.5 & 28 & 39.9 & 39 & 38.0 \\
\hline 7 & 39.2 & 18 & 38.4 & 29 & 37.4 & 40 & 37.2 \\
\hline 8 & 39.0 & 19 & 37.2 & 30 & 37.5 & 41 & 37.3 \\
\hline
\end{tabular}


International Journal of Electronics and Applied Research (IJEAR)vol. 6, issue 2, Dec 2019 Online (http://eses.net.in/online_journal.html)

\begin{tabular}{|l|l|l|l|l|l|l|l|}
\hline 9 & 35.3 & 20 & 36.4 & 31 & 36.7 & 42 & 37.4 \\
\hline 10 & 36.8 & 21 & 36.7 & 32 & 35.7 & 43 & 38.8 \\
\hline 11 & 38.6 & 22 & 36.0 & 33 & 37.4 & & \\
\hline
\end{tabular}

Here the observed values $x_{i}(i=1,2,3$, 43) can be assumed to be composed of a parameter $\mu$ (representing the central tendency of annual maximum) and random errors so that the observed values follow the model described by equation (1.1).

\section{Evaluation of Value of $\mu$ (the central tendency of annual maximum)}

The computed values of arithmetic mean and the geometric mean of the observed values, shown in Table-3.1.1, are found to be

\subsection{4 and 37.192287148576076781925812747586}

respectively.

Let us write

$$
\begin{aligned}
A_{0} & =37.2093023255814 \\
\& \quad G_{0} & =37.192287148576076781925812747586
\end{aligned}
$$

In this case the iterations give the values which are given in the following table (Table - 3.1.2):

Table $-\mathbf{3 . 1 . 2}$

\begin{tabular}{|l|l|l|}
\hline$n$ & \multicolumn{1}{|c|}{$A_{n}$} & \multicolumn{1}{c|}{$G_{n}$} \\
\hline 0 & $\underline{37.2093023255814}$ & $\underline{37.192287148576076781925812747586}$ \\
\hline 1 & $\underline{37.200794737078738390962906373793}$ & $\underline{37.20079376426265222211622224967}$ \\
\hline 2 & $\underline{37.200794250670695306539564311732}$ & $\underline{\underline{37.200794250670692126596916004529}}$ \\
\hline 3 & $\underline{37.200794250670693716568240158131}$ & $\underline{37.20079425067069371656824015813}$ \\
\hline
\end{tabular}

The digits in $A_{n}$ and $G_{n}$, which are agreed, have been underlined in the above table.

The AGM of

$$
37.2093023255814 \text { and } 37.192287148576076781925812747586
$$

is the common limit of these two sequences which is 


\subsection{3}

Thus the value of $\mu$, the central tendency of annual maximum of surface air temperature at Guwahati, is 37.20079425067069371656824015813 Degree Celsius.

\subsection{Annual Minimum of Surface Air Temperature at Guwahati:}

The following table (Table - 3.2.1) shows the observed data on annual maximum of surface air temperature, occurred in temperature periodic year (TPR), at Guwahati during the period from1969 to 2013.

As earlier, the observed values

$x_{i}(i=1,2,3$

can in this case also be assumed to be composed of a parameter $\mu$ (representing the central tendency of annual minimum) and random errors so that the observed values follow the model described by equation (1.1).

Table - 3.2.1

Observed Value on Annual Minimum of Surface Air Temperature (in Degree Celsius)

\begin{tabular}{|c|c|c|c|c|c|c|c|}
\hline $\begin{array}{c}\text { TPR No } \\
(i)\end{array}$ & $\begin{array}{c}\text { Observed } \\
\text { Value }\left(x_{i}\right)\end{array}$ & $\begin{array}{c}\text { TPR No } \\
\text { (i) }\end{array}$ & $\begin{array}{c}\text { Observed } \\
\text { Value }\left(x_{i}\right)\end{array}$ & $\begin{array}{c}\text { TPR No } \\
\text { (i) }\end{array}$ & $\begin{array}{c}\text { Observed } \\
\text { Value }\left(x_{i}\right)\end{array}$ & $\begin{array}{c}\text { TPR No } \\
(i)\end{array}$ & $\begin{array}{l}\text { Observed } \\
\text { Value }\left(x_{i}\right)\end{array}$ \\
\hline 1 & 6.6 & 12 & 6.4 & 23 & 7.4 & 34 & 8.0 \\
\hline 2 & 6.6 & 13 & 7.5 & 24 & 5.9 & 35 & 7.9 \\
\hline 3 & 5.9 & 14 & 8.3 & 25 & 8.4 & 36 & 6.7 \\
\hline 4 & 8.2 & 15 & 4.9 & 26 & 7.8 & 37 & 9.6 \\
\hline 5 & 5.0 & 16 & 6.1 & 27 & 7.5 & 38 & 6.4 \\
\hline 6 & 6.3 & 17 & 7.8 & 28 & 9.4 & 39 & 7.8 \\
\hline 7 & 7.4 & 18 & 8.6 & 29 & NA & 40 & 9.9 \\
\hline 8 & 6.6 & 19 & 7.7 & 30 & NA & 41 & 8.6 \\
\hline 9 & 6.2 & 20 & 9.2 & 31 & NA & 42 & 7.0 \\
\hline 10 & 7.3 & 21 & 6.7 & 32 & 8.9 & 43 & 6.4 \\
\hline
\end{tabular}


International Journal of Electronics and Applied Research (IJEAR)vol. 6, issue 2, Dec 2019 Online (http://eses.net.in/online_journal.html)

6.2

22

8.6

33

8.6

44

5.6

\section{Determination of Value of $\mu$ (the central tendency of annual minimum)}

The computed values of arithmetic mean and the geometric mean of the observed values, shown in Table - 3.1.1, are found to be

\subsection{2 and 6.9882108302873798619833480810597}

Let us write

$$
\begin{aligned}
& A_{0}=7.032 \\
& \& \quad G_{0}=6.9882108302873798619833480810597
\end{aligned}
$$

In this case the iterations give the values which are given in the following table (Table - 3.2.2):

Table - 3.2.2

\begin{tabular}{|l|l|l|}
\hline$n$ & \multicolumn{1}{|c|}{$A_{n}$} & \multicolumn{1}{c|}{$G_{n}$} \\
\hline 0 & 7.032 & 6.9882108302873798619833480810597 \\
\hline 1 & $\underline{7.0101054151436899309916740405299}$ & $\underline{7.01007122350271525324088557295979}$ \\
\hline 2 & $\underline{7.0100883193232025921162798850639}$ & $\underline{7.0100883193023564155188951988585}$ \\
\hline 3 & $\underline{7.0100883193127795038175875419612}$ & $\underline{7.0100883193127795038175797930738}$ \\
\hline 4 & $\underline{7.0100883193127795038175836675175}$ & $\underline{7.0100883193127795038175836675175}$ \\
\hline
\end{tabular}

The digits in $A_{n}$ and $G_{n}$, which are agreed, have been underlined in the above table.

The AGM of

$$
7.032 \text { and } 6.9882108302873798619833480810597
$$

is the common limit of these two sequences which is

$$
7.0100883193127795038175836675175
$$

Thus the value of $\mu$, the central tendency of annual minimum of surface air temperature at Guwahati, is 7.0100883193127795038175836675175 Degree Celsius. 


\section{Conclusion}

The methods developed so far, for determining thr appropriate value of the parameter from observed data containing the parameter itself and random error involve huge computational tasks. The method described here involves lesser computational tasks than those involved in the methods developed so far.

Moreover, a finite set of observed data may not yield the appropriate value of the parameter in many situations while the number of observations required in the methods may be too large for obtaining the appropriate value of the parameter. The method described here can be applicable in the case of finite set of data.

Regarding the findings obtained on annual maximum and annual minimum of surface air temperature at Guwahati, the following conclusion can be drawn:

4.1. The value of central tendency of annual maximum of surface air temperature at Guwahati has here been obtained as 37.20079425067069371656824015813 Degree Celsius. However, the value of the same was found to be 37.2 Degree Celsius by the earlier methods of the same [2014c , 2015a , 2015b , 2015c , 2015d , 2015e , 2017 , 2018a 2019b]. This means, the method developed here can yield more accurate value.

4.2. The central tendency of annual maximum of surface air temperature at Guwahati has here been obtained as 7.0100883193127795038175836675175 Degree Celsius. However, it was found not possible to obtain the value of central tendency of the same by the earlier methods [2014c , 2015a , 2015b , 2015c , 2015d , 2015e , 2017 , 2018a 2019b].

\section{References:}

Aldrich John, Fisher's Inverse Probability of 1930, International Statistical Review, Vol. 68, pp. $155-172,2000$.

Anders Hald, On the History of Maximum Likelihood in Relation to Inverse Probability and Least Squares, Statistical Science, Vol. 14, pp. 214 - 222, 1999.

Barnard G. A., Statistical Inference, Journal of the Royal Statistical Society, Series B, Vol. 11, pp. $115-149,1949$. 
Birnbaum Allan, On the Foundations of Statistical Inference, Journal of the American Statistical Association, Vol. 57, pp. 269 - 306, 1962.

Chakrabarty Dhritikesh, Determination of Parameter from Observations Composed of Itself and Errors, International Journal of Engineering Science and Innovative Technology, 3(2), (ISSN : 2139 - 5967), $304-311,2014 a$.

Chakrabarty Dhritikesh, Analysis of Errors Associated to Observations of Measurement Type, International Journal of Electronics and Applied Research (ISSN : 2395 - 0064), 1(1), 15 - 28 , $2014 b$.

Chakrabarty Dhritikesh, Observation Composed of a Parameter and Random Error: An Analytical Method of Determining the Parameter, International Journal of Electronics and Applied Research (ISSN : 2395 - 0064), 1(2), 20 - 38, 2014c.

Chakrabarty Dhritikesh, Observation Consisting of Parameter and Error: Determination of Parameter, Proceedings of the World Congress on Engineering 2015, (WCE 2015, July 1 - 3, 2015, London, U.K.), ISBN: 978-988-14047-0-1, ISSN: 2078-0958 (Print); ISSN: 2078-0966 (Online), Vol. II, $680-684,2015 a$.

Chakrabarty Dhritikesh, Central Tendency of Annual Extremum of Surface Air Temperature at Guwahati, J. Chem. Bio. Phy. Sci. (E- ISSN : 2249 - 1929), Sec. C, 5(3), 2863 - 2877, $2015 b$.

Chakrabarty Dhritikesh, Central Tendency of Annual Extremum of Surface Air Temperature at Guwahati Based on Midrange and Median, J. Chem. Bio. Phy. Sci. (E- ISSN : 2249 - 1929), Sec. D, 5(3), $3193-3204,2015 c$.

Chakrabarty Dhritikesh, Observation Composed of a Parameter and Random Error: Determining the Parameter as Stable Range, International Journal of Electronics and Applied Research (ISSN : 2395 - 0064), 2(1), 35 - 47, 2015d.

Chakrabarty Dhritikesh, A Method of Finding Appropriate value of Parameter from Observation Containing Itself and Random Error, Indian Journal of Scientific Research and Technology, (EISSN: 2321-9262), 3(4), $14-21,2015 e$.

Chakrabarty Dhritikesh, Theoretical Model Modified For Observed Data: Error Estimation Associated To Parameter, International Journal of Electronics and Applied Research (ISSN : 2395 - 0064), 2(2), 29 - 45, $2015 f$.

Chakrabarty Dhritikesh, Impact of Error Contained in Observed Data on Theoretical Model: Study of Some Important Situations, International Journal of Advanced Research in Science, Engineering and Technology, (ISSN : 2350 - 0328), 3(1), 1255 - 1265, $2016 a$. 
Chakrabarty Dhritikesh, Theoretical Model and Model Satisfied by Observed Data: One Pair of Related Variables, International Journal of Advanced Research in Science, Engineering and Technology, (ISSN : 2350 - 0328), 3(2), 1527 - 1534, $2016 b$.

Chakrabarty Dhritikesh, Numerical Data Containing One Parameter and Random Error: Evaluation of the Parameter by Convergence of Statistic, International Journal of Electronics and Applied Research (ISSN : 2395 - 0064), 4(2), 59 - 73, 2017.

Chakrabarty Dhritikesh, Observed Data Containing One Parameter and Random Error: Evaluation of the Parameter Applying Pythagorean Mean, International Journal of Electronics and Applied Research (ISSN : 2395 - 0064), 5(1), 32 - 45, 2018a. Online (http://eses.net.in/ESES Journal).

Chakrabarty Dhritikesh, Derivation of Some Formulations of Average from One Technique of Construction of Mean, American Journal of Mathematical and Computational Sciences, 3(3), 62 $-68,2018 b$.

Chakrabarty Dhritikesh, One Generalized Definition of Average: Derivation of Formulations of Various Means, Journal of Environmental Science, Computer Science and Engineering \& Technology, Section C, (E-ISSN : 2278 - 179 X), 7(3), 212 - 225, $2018 c$.

Chakrabarty Dhritikesh, $f_{H}$ - Mean: One Generalized Definition of Average, Journal of Environmental Science, Computer Science and Engineering \& Technology, Section C, (E-ISSN : $2278-179 \mathrm{X}), 7(4), 301-314,2018 d$. Also available in www.jecet.org.

Chakrabarty Dhritikesh, Generalized $f_{G}$ - Mean: Derivation of Various Formulations of Average, American Journal of Computation, Communication and Control, 5(3), 101 - 108, 2018e. Available in http://www.aascit.org/journal/ajmcs .

Chakrabarty Dhritikesh, Significance of Change of Rainfall: Confidence Interval of Annual Total Rainfall, Journal of Chemical, Biological and Physical Sciences (E- ISSN : 2249 - 1929), Sec. C, 9(3), 151 - 166, 2019a. Available at: www.jcbsc.org.

Chakrabarty Dhritikesh, Observed Data Containing One Parameter and Random Error: Probabilistic Evaluation of Parameter by Pythagorean Mean, International Journal of Electronics and Applied Research (ISSN : 2395 - 0064), 6(1), 24 - 40, 2019b. Online (http://eses.net.in/ESES Journal).

Chakrabarty Dhritikesh, Significance of Change in Surface Air Temperature in the Context of India, Journal of Chemical, Biological and Physical Sciences (E- ISSN : 2249 - 1929), Sec. C, 9(4), $251-261,2019 c$. Online available at: www.jcbsc.org .

Chakrabarty Dhritikesh, One General Method of Defining Average: Derivation of Definitions/Formulations of Various Means, Journal of Environmental Science, Computer 
Science and Engineering \& Technology, Section C, (E-ISSN : 2278 - 179 X), 8(4), 327 - 338 , $2019 d$. Also available in www.jecet.org .

Chakrabarty Dhritikesh, A General Method of Defining Average of Function of a Set of Values, Aryabhatta Journal of Mathematics \& Informatics \{ISSN (Print) : 0975-7139, ISSN (Online) : 2394-9309\}, 11(2), $269-284,2019 e$. Also available in www.abjni.com .

Cornelli G., McKirahan R. \& Macris C, On Pythagoreanism, Berlin, Walter de Gruyter, 2013.

de Carvalho Miguel, Mean, what do you Mean?, The American Statistician, 70, 764 -776, 2016.

David A. Cox, The Arithmetic-Geometric Mean of Gauss, In J.L. Berggren; Jonathan M.

Borwein; Peter Borwein (eds.). Pi: A Source Book. Springer. p. 481. ISBN 978-0-387-20571-

7. first published in L'Enseignement Mathématique, t. 30 (1984), p. 275-330, 2004

Hazewinkel, Michiel, ed., Arithmetic-geometric mean process, Encyclopedia of Mathematics, Springer Science+Business Media B.V. / Kluwer Academic Publishers, ISBN 978-1-55608-0104, 2001.

Ivory, On the Method of Least Squares, Phil. Mag., LXV, 3 - 10, 1825.

Kendall M. G. and Stuart A, Advanced Theory of Statistics, Vol. $1 \& 2,4^{\text {th }}$ Edition, New York, Hafner Press, 1977.

Kolmogorov Andrey, On the Notion of Mean, Mathematics and Mechanics, 199(1), 144 - 146, 1930.

Lehmann Erich L. \& Casella George, Theory of Point Estimation, 2nd ed. Springer. ISBN 0 $387-98502-6,1998$.

Lucien Le Cam, Maximum likelihood - An introduction, ISI Review, 58 (2), 153 -171, 1990.

Michiel ed. Hazewinkel, Normal Distribution, Encyclopedia of Mathematics, Springer, ISBN $978-1-55608-010-4,2001$.

Walker Helen M. \& Lev J., Statistical Inference, Oxford \& IBH Publishing Company, 1965.

O'Meara Dominic J., Pythagoras Revived: Mathematics and Philosophy in Late Antiquity, $\underline{\text { ISBN }}$ 0-19-823913-0, Clarendon Press, Oxford, 1989.

Riedweg Christoph, Pythagoras: his life, teaching, and influence (translated by Steven Rendall in collaboration with Christoph Riedweg and Andreas Schatzmann, Ithaca), ISBN 0-8014-4240-0, Cornell University Press, 2005. 
Weir, Alan J., The Convergence Theorems, Lebesgue Integration and Measure. Cambridge: Cambridge University Press. pp. 93-118. ISBN 0-521-08728-7. 1973.

Yeh, J., "Real Analysis: Theory of Measure and Integration", Hackensack, NJ: World Scientific. ISBN 981-256-653-8, 2006. 